\title{
PERFORMANCE AND KEY FACTORS OF CLOUD COMPUTING IMPLEMENTATION IN THE PUBLIC SECTOR
}

\author{
Hasimi Sallehudin* \\ Universiti Kebangsaan Malaysia \\ Azana Hafizah Mohd Aman \\ Universiti Kebangsaan Malaysia \\ Razli Che Razak \\ Universiti Malaysia Kelantan \\ Mohammad Ismail \\ Universiti Malaysia Kelantan \\ Nur Azaliah Abu Bakar \\ Universiti Teknologi Malaysia
}

Ahmad Firdause Md Fadzil

University of Sultan Zainal Abidin

Rogis Baker

National Defence University of Malaysia

\begin{abstract}
The reason to explain the cloud computing assimilation, as well as the understanding of the operational performance, still remains unclear. To investigate this issue, this study has examined the assimilation of cloud computing by examining the organization's implementation of cloud computing and performance in the Malaysian public sector. Grounded by the Diffusion of Innovation Theory (DOI), Technology-OrganizationEnvironment Framework (TOE) and IS Success Model. This study proposes a framework by decomposing Technological characteristic, Organizational characteristics, Environmental characteristics and Human characteristics as factors. A total of 169 agencies from the Malaysian public sector have participated in this study. Data for all the study variables have been collected through self-administered survey questionnaires and analysed using SEM-PLS. The study has shown that the effect of the operational effectiveness of cloud implementation is at a lower level. The study also reveals that factors of relative advantage, compatibility, perceived risks, top management support, and organizational readiness are found to have a significant effect on cloud computing implementation. However, both external support and government regulations are not significant to the cloud computing implementation in the Malaysian public sector. The results indicate that the model provides a good understanding of the factors that influence the implementation of cloud computing as well as operational performance.
\end{abstract}

- Corresponding author: Fakulti Teknologi dan Sains Maklumat, Universiti Kebangsaan Malaysia, UKM Bangi, 43600 Bangi, Selangor. hasimi@ukm.edu.my 
Keywords: Cloud computing; Implementation; Public sector; Performance; TOE framework; IS Success Model

Received: 11 August 2018

Accepted: 30 December 2019

\section{INTRODUCTION}

The adoption and implementation of new IT innovation continue to be an interesting research topic. The advancement of IT innovation implementation provides organizations the excess for potential opportunities to increase efficiency, enhance services, lower costs, and improve business value. As IT innovation implementation becomes an increasingly integral aspect of organizations, decision makers must understand the forces and factors that shape the adoption and implementation decision. However, this decision is far from simple. In today's dynamic, global, and highly competitive business environment, executives and IT decision makers must make smart and valuejustified decisions about their technology implementation, investment and strategy (Laudon \& Laudon, 2010; Tarute \& Gatautis, 2014). Organizations must carefully assess their current state of IT environment, determine potential gaps, identify opportunities, evaluate a range of IT options, and select the right solutions that can meet their immediate needs and align with their long-term business goals.

In many cases, IT adoption decisions are further complicated by incompatible and complexity of innovation, uncertainty for risks, lacks organizational readiness, stakeholders' pressure and requirement, regulatory influences, and supplier forces (Ayyash et al., 2012; Hong \& Zhu, 2006; Premkumar, 2003; Ramdani et al., 2013; Ramdani et al., 2009). In addition, contextual factors often shape the decisions organizations make with respect to their IT implementation investments. The complexity of the technology decision increases even further when the IT under consideration is just emerging and its value is still unknown. For instance, the decision of the latest IT innovation such as virtualization, green computing, and cloud computing adoption among businesses and governments around the world is not growing as fast as expected even though it provides both strategic and operational advantages to its adopters (Buyya et al. 2009; Low et al. 2011).

In relation with the emergence of new technologies in the era of Industry Revolution 4.0 (IR4.0) such as cloud computing, organizations' innovativeness in adopting these technologies varies distinctly (Li et al. 2015). Although the technologies are proclaimed to provide numerous benefits to the organizations, the acceptance of cloud computing services and resources among organization has been far from expectations (Buyya et al., 2009; Low et al., 2011). Many organizations are undertaking cloud computing services and resources initiatives quite cautiously by taking one step at a time or preferring to 'wait-and-see'. Hence, it is imperative that a study on cloud computing services and resources adoption in an organization is carried out to determine the factors that influence organizations' propensity to adopt technologies. Our assertion is supported by the Cisco Internet Business Solutions Group (IBSG), which has identified the topic of cloud computing services and resources adoption, and measuring economics survive today as a critical strategy for the organization and become the main research priority for 2013 to 2020 (Williams, 2012).

In the Malaysian Public Sector, the government cloud initiatives or MyGovCloud (formally known as 1 GovCloud) was introduced and officially launched in July 2013 to embark the initiative of 
National Digital Economy. MyGovCloud offers cloud hosting that provides a number of resources (network, storage, server and operating system) to the agency. The deployment model of MyGovCloud is based on a private cloud and the service is based on Infrastructure as a Service (IaaS). Until now, a total of 250 applications that included in MyGovCloud such as MyMTC, MyMesyuarat, MAMPU website, MyRELA website, and e-Solat JAKIM. The MyGovCloud services are offered to all seven hundred thirty (730) organization in the Malaysian public sector which covers all federal central agencies, federal operating agencies, and state operating agencies. However, recent statistic from MAMPU stated that there were only 61 public agencies utilized the MyGovCloud services while majority of agencies prefer to operate their own data centres, even though they have already subscribed to MyGovCloud (Amron et al., 2018; Sallehudin et al., 2019).

Based on the issue highlighted, there is a lack of studies regarding the IT effectiveness in the public sector. Several initiatives have been taken by the Malaysian government to adopt IT innovation such as cloud models for optimizing digital economy practices. However, the effectiveness measures in this study is sufficient to explain that cloud computing implementation is significant to the performance on IT effectiveness (Sallehudin et al., 2019). Therefore, this study concerns to understand what are the hindering factors in the implementation of cloud computing services in the Malaysian Public Sector context by deriving an integrated information system theory models used by similar studies. This is highly relevant theoretically and practically, since despite of mega implementation of cloud computing initiative by the government, it seems that not all government agencies fully utilizing the cloud computing infrastructure and services provided. Hence, the central aim of this study is to examine the influence factors related to cloud computing services assimilation and its operational effectiveness in the Malaysian public sector. Determining the key factors that contribute to the implementation of cloud services in Malaysia is essential. Without understanding the diversity factors affecting complex processes and stages of cloud computing implementation, the drive to adopt and develop cloud computing implementation will not effectively contribute to the public sectors' IT effectiveness (Amron et al., 2018; Meri et al., 2019; Mukred et al., 2017; Sallehudin et al., 2016). Therefore, this study aims to fill this gap by investigating technological, organizational and environment affecting cloud computing implementation by the public sector.

\section{THEORETICAL FOUNDATION}

The spread of innovation theory (DOI) from Rogers (2003) is often used to describe adoption and acceptance of innovation, especially in the fields of IT research. Rogers focuses on connecting ideas which consist of ideas, processes, and technologies throughout the interval between members in the social system. According to Rogers (2003), participants of the social system are adopters who can be individuals, organizations or communities. Rogers's DOI theorizes that five innovations characteristics - relative advantage, compatibility, complexity, trialability and observation; make it easier for technology innovation to adopted and faster dissemination. Research on the use of innovation has explored the factors that affect the adoption of technological innovation using these characteristics. However, the nature of technology is characterized by the main objectives context of the technology itself (e.g. cloud computing technology), rather than the independent context, such as the nature of the decision maker as well as regulatory and environmental factors (internal or external). 
Another model of technology adoption that is the basis for many investigations of information systems (IS) use in organizational levels is the TOE framework. This model discusses the predictors of information systems penetration by Tornatzky and Fleischer (1990). The TOE framework is an organizational ranking model that describes three different context attributes of a company that influence the decision on use. These three elements are technology, organization and environment. Technological backgrounds represent technological and innovation characters used by organizations. The organizational context refers to the characteristics of the company, such as the size of the organization and the volume of resources. Finally, the context of the environment illustrates the structure of the industry and the environment surrounding the organization that conducts the business. The TOE model suggests that the attributes of the three contexts will influence the use of innovation within the organization particularly cloud computing (Sallehudin et al., 2019; Hassan et al., 2017).

Next, the IS success is one of the most studied topics in information systems literature (Ayyash et al., 2012). Measuring IS success is considered a critical issue in the IS field. Several studies have been conducted and many attention has been given to this problem because of the amount of funds, time and effort spent on the IT projects (Mohammed \& Ibrahim, 2015; Syed et al., 2018). IS literature have some definitions and dimensions of IS success. As DeLone and McLean (1992) stated that, even though there are many measurement in the studies; evidently there is no decisive definition of IS success. The definition of IS success can vary depending on different IT types that provide different benefits to individuals, working groups, and organizations. Based on definitions and construct conceptualization by DeLone and McLean's (2003) and IS success model, this study conceives Ramamurty's (1990) implementation outcome as in reduced IT operating cost as well as principal to enhanced productivity and quality in service delivery. Therefore, this study defines the Malaysian Public Sector cloud computing implementation particularly on its effect to operational efficiency as a success measure in this context.

\section{RESEARCH MODEL AND HYPOTHESES}

Based on the work of DeLone and McLean (1992) and Tornatzky and Fleischer (1990) a theoretical-based model for cloud computing implementation using a TOE framework and IS Success Model was developed and is depicted in Figure 1. The implementation variable in the model is not acting as mediator. It is a sequence of events to implement then followed with consequences after the implementation, which is in this study conceptualized as operational effectiveness. More specifically, it is similar to the sequent of events in TAM model for behavioral intention to actual use (Davis, 1989).

\subsection{Technology Context}

In this study, the technological context characterizes cloud computing characteristics such as relative advantage and compatibility. Both factors might determine the likelihood might stimulate of cloud computing implementation by the Malaysian public sector. Both the DOI theory and TOE model of IT innovation emphasize on the importance of the innovation factor to the implementation of IT innovation. 
Relative advantage is perceived as benefits for an organization over previous ways of completing the same task (Alam et al., 2011; Moore \& Benbasat, 1991). Relative advantage has been found to be one of the dominant factor and completely correlated to an IT innovation implementation. For instance, a recent study by Sallehudin et al. (2019) confirmed that the relative advantage of cloud computing is positively associated with cloud computing adoption within the SMEs in Malaysia. In view of the benefits that cloud computing compromises, the Malaysian public sector who perceived cloud computing as advantageous would likely to adopt cloud computing hence enhance their service delivery. Therefore, the following hypotheses were proposed.

\section{H1: Relative advantage positively affects the implementation of cloud computing.}

Cloud computing compatibility refers to the degree to which cloud computing is compatible with an organization's values and beliefs. The questions measure respondent's perspective in terms of the compatibility of the cloud computing on the current aspect of IT system or services in the agency and the fitness of cloud computing to be integrated with the current IT systems (Sallehudin et al., 2019). In the Malaysian public sector, most of the traditional or incumbent systems and technology infrastructure are based on the famous and known technology solutions such as Microsoft, Linux, Oracle, Cisco, and etc. This technology supports cloud computing compatibility. Therefore, the following hypotheses were proposed.

H2: $\quad$ Compatibility positively affects the implementation of cloud computing.

Figure 1: Research Model

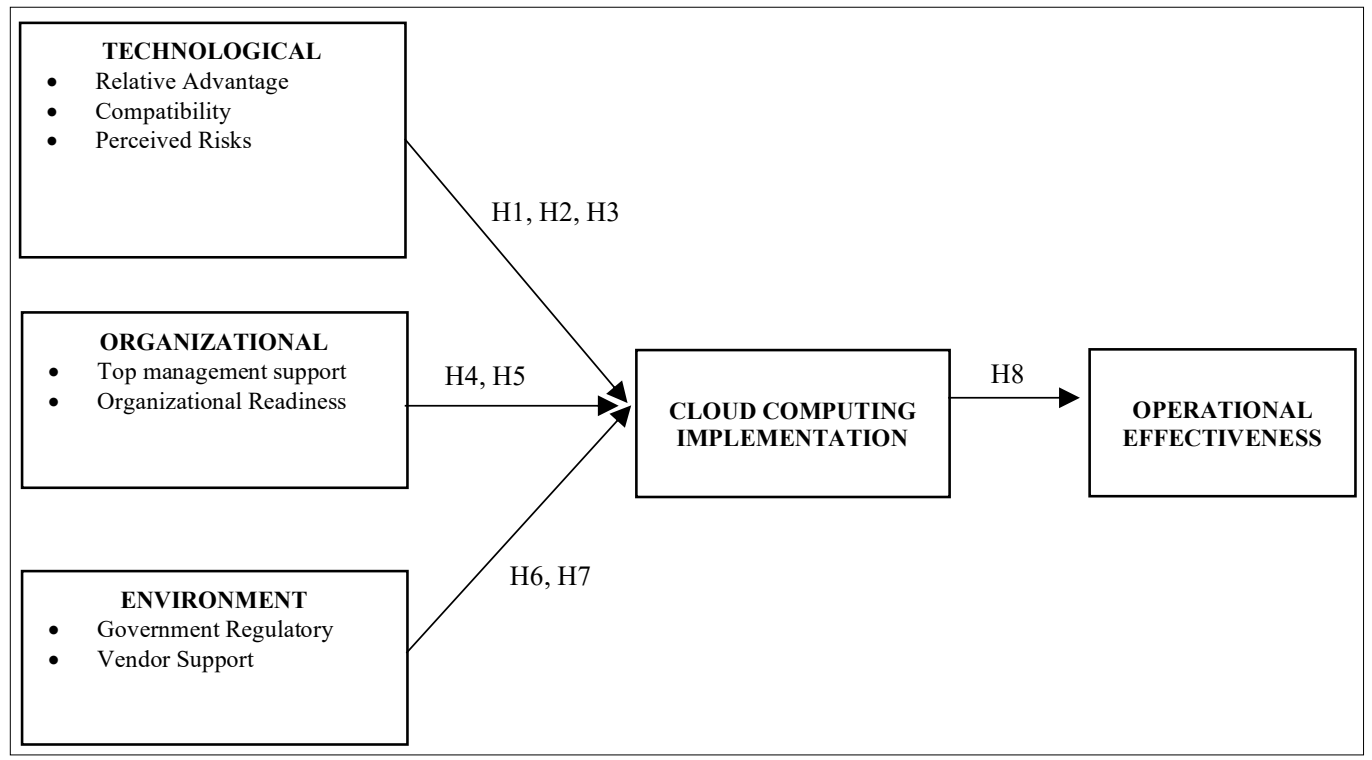

The literature identifies perceived risks as an essential element of a relationship when security, trust or uncertainty is present (Akturan \& Tezcan, 2012; Chen, 2013; Gewald \& Dibbern, 2009; Horst et al., 2007; Oh et al., 2012). The intention to focus on implication and impact of the 
perceived risk factor in this study is because recents studies reveals that the dark side of cloud computing are the security concerns which become a main barrier toward cloud computing acceptance, adoption and implementation (Buyya et al., 2009; Jaatun et al., 2012; Wyld, 2010). Despite vendor claims to improved security through improved expertise and redundancy, security remains a sticking point for the cloud computing model. A customer of cloud computing will lose control over their resources. They only provided with access to the subscribed package.

In a highly sensitive situation, security and other business requirements customised by the vendors but with the extra and special setting and it's involved with a high cost. Data integrity and privacy were other issues in cloud computing models (Sallehudin et al., 2019; Wyld, 2010). In traditional infrastructure environment, the organization has full control over their sensitive and confidential data within the organization or secret data recovery centre in other places. However, in a cloud computing environment, the organization will lose its control over access to sensitive and confidential data because the data is stored outside of their premises or country. In the public sector particularly in the Malaysian public sector, security and confidentiality of the data are the main focus for any new IT innovation implementation (Safie et al., 2017). Therefore, perceived risk factors will negatively influence this relationship when it compromises to IT security breach as a big issue in the public sector. Therefore, the following hypotheses were proposed.

\section{H3: $\quad$ Perceived Risks are less likely to affects the implementation of cloud computing.}

\subsection{Organization Context}

The organization context signifies the organizational elements, which is described by this study as the element of the agencies in the Malaysian public sector that determine its influence to adopt cloud computing. The TOE emphasizes the prominence of the organizational factor to the adoption of innovation. Commitment and support by top management structure are shown to be a favour for the acceptance of technological innovation in adopting organization (Alshamaila \& Papagiannidis, 2013; Borgman et al., 2013; Low et al., 2011; Ifinedo, 2010; Tornatzky \& Fleischer, 1990).

The influence of top management acts as change agents in the decision process. The decision could be positive or negative to the adoption. The positive decision by top management will create full support to the adoption process and leads to project implementation success. In the context of cloud computing, this innovation provides a better solution for business process both in technical and non-technical. For the technical view, cloud computing offers 3 types of service and 4 implementation models as discussed previously. From a non-technical point of view which is considered as benefits for business advantage, cloud computing offers elasticity, simplicity, shared-services, enhanced service delivery and collaboration solution for competitive advantage that leads to greater achievement for e-government service sustainability. Therefore, the following hypotheses were proposed.

\section{H4: $\quad$ Top Management Support positively affects the implementation of cloud computing.}

Organizational readiness represents the internal IT maturity for new innovation implementation. The availability of financial, human and technical readiness should be adequate with the related of 
new innovation that will be implemented (Yusof \& Arifin, 2016). In the context of Malaysian public sector, agency's readiness would cover all these three aspects; adequate cost, competence human resources (IT staff) for support and troubleshoot, and sufficient technological/technical infrastructure. A prior study found that organizational readiness was the significant factor for IT innovation adoption such as enterprise resource planning (ERP), e-business and knowledge management system (Lin, 2012). New IT innovation implementation without organizational readiness in terms of inadequate financial, incompetence or insufficient IT staff support and lack of technological infrastructures will create problem to the implementation project and sometimes the project was delayed or failed.

For cloud computing implementation in the Malaysian public sector, the agency should ready with competence IT staff to support and troubleshoot the services during and after implementation. Agency also should have sufficient computer network infrastructure with a reliable internet connection and faster download/upload speed. This is because access to cloud computing services is via computer networking infrastructure. Unreliable internet connection and slow download/upload speed in the agency will create problem or disruption of services, thus will lead to the failure of cloud computing implementation. Therefore, the following hypotheses were proposed.

\section{H5: Organizational Readiness positively affects the implementation of cloud computing.}

\subsection{Environmental Context}

The environmental factor represents the environmental characteristics, which can be defined as the characteristics of the environment in which the agencies run its business that may contribute in creating the need for an ability to adopt and implement the cloud computing innovation. The TOE framework emphasizes the importance of the environmental factor to the adoption of innovation. However, the environmental factor needs to be modified based on the current issues and problems identified at the organizational-level adoption of innovations in the Malaysian public sector agencies. Many studies have emphasized the importance of the environmental factor to the adoption of IT innovation (e.g. Alshamaila \& Papagiannidis (2013); Lin (2013)).

The IT innovation implementation in the public sector is an internal arrangement within the IT department and another department such as finance, human resource and management board or council to support an approval. There is a body of research showing that the assistance of external IT experts, consultants and vendors, and their quality are some of the most important aspects of the IS implementation among organizations (Ghobakhloo \& Tang, 2015). As explained previously, most agencies in the Malaysian public sector are suffering from a lack of internal IT expertise (MAMPU, 2011). Since this issue is a significant barrier to the IT development and advancement within the Malaysian public sector, they must overcome this problem through either seeking help from external sources or developing their own internal cloud computing skills. Consistently, Kaliannan, Raman, \& Dorasamy (2009) empirically demonstrated that IT usage within organizations hiring external consultants has been higher than usage among organizations without consultants. It was also reported that user satisfaction with IT among organizations is also affected significantly by external IT assistance. The author consistently argues that public sectors, especially in developing countries are suffering from severe lack of IT knowledge, skills and 
supports (Ghobakhloo \& Tang, 2015), therefore, it is imperative for these organizations to frequently seek assistance from external experts to lower their IT innovation barrier.

On the other hand, technology providers or vendors often try to promote the adoption of new technology by giving discounts or incentives on new technology purchases, offering competitive upgrades to newer technology, providing free help and training to potential customers (Maclennan $\&$ Belle, 2014). Thus, all this will provide direct support for IT innovation implementation. In addition, various external IT integration and development tools supporting heterogeneous environments and runtime monitoring tools are important in the cloud computing environment for the public sector. Therefore, the following hypotheses were proposed.

\section{H6: $\quad$ External IS support positively affects the implementation of cloud computing.}

Government regulatory supports is found to be another critical environmental factor that tends to affect innovation diffusion. In the Malaysian public sector, government regulatory supports are the directives or circulars from Chief Secretary of the Government (KSN), federal ministries or central agencies such as MAMPU, regarding the implementation of certain policies or procedures for adoption, along with a set of specific deadlines. In response to such directives, a series of actions will follow where agencies will instruct their internal department to act accordingly. The directives or circulars could be as a mandated, voluntary and guidelines for agencies to comply. For mandated directive, agencies must obey the rules and guidelines provided. For instance, the 5-years Public Sector ICT Blueprint that was developed by MAMPU triggered the development of agency-specific ICT Strategic Plans (ISP) across the nation, in an effort to enhance nationwide public service delivery. In another example of mandated directive and guidelines is the approval for IT projects (MAMPU, 2015), data center management guidelines (Garis Panduan Pengurusan Pusat Data, 2011) and ICT security policy in agencies (MAMPU, 2000). For a voluntary situation, agencies are not forced to follow or implement the directive order but they can follow the guidelines provided for reference. The example of the voluntary directive is the implementation of an open source system in agencies.

In other situation, agencies can adopt and implement any of IT innovation to the organization by their own accord without a directive from central agencies. In this case, the organization need to provide justification and project paper for financial approval by MAMPU and Economic Planning Unit (EPU) in the Prime Minister Department. Cloud computing implementation with a directive from MAMPU will be easily to receive support in terms of human resource, management and financial within the organization. Therefore, the following hypotheses were proposed.

\section{H7: Government regulatory support positively affects the implementation of cloud computing.}

\subsection{Cloud computing Effectiveness}

The benefits of cloud computing in the public sector are also reflected in the use of an expanded IT to create government value. For instance, in the virtualization environment (Buyya et al., 2011), the characterization of a cloud computing system allows adopters to feel the needs of the service provision and improve the capacity of the corresponding organization by unifying the IT infrastructure throughout the organization. With that environment, the organizations can evaluate 
or stimulate stakeholder' requests accurately and seek the provision of services provided by the government. As such, the extent of cloud computing implementation can lead to enhance productivity and quality in service delivery (Armbrust et al., 2010; Buyya et al., 2011).

In addition, the cloud computing implementation benefits the IT procurement cost by saving the procuring of redundancies hardware and software across agencies in the public sector as well as improves IT staff utilization. Cloud computing offers inexpensive, faster, reduced inventory, enhance the effectiveness of logistics, as well as improved access to IT services (Armbrust et al., 2010; Buyya et al., 2011). For instance, one platform of IT server or data centre can be consolidated by many organizations. As such, the operational IT services by one agency can be shared by other agencies may reduce the IT operational cost for the entire organization. From the purchasing government's point of view, cloud computing facilitates procurement innovations to result in a reduced purchased price, reduced cycle time and improved IT sourcing (Craig et al., 2009; Wyld, 2009). Thus, the cost savings and efficiencies associated with cloud computing implementation would result in reduced IT operating cost, which in tum result in better financial performance thus improve the operational effectiveness. Therefore, the following hypothesis was proposed.

\section{H8: The implementation of cloud computing technology positively affects operational effectiveness}

\section{RESEARCH METHOD}

The population for this study was the agencies, departments and ministries in the Malaysian public sector. Currently, there are seven hundred thirty (730) organization in the Malaysian public sector enterprise. These organizations can be categorized into three administrative groups; federal central agencies, federal operating agencies, and state operating agencies. To represent all of these organizations, IT personnel at each of these organizations will appoint as appropriate respondents to answer the questionnaire for this study. Stratified sampling techniques used to identify the organizations to be as respondents. Based on Hair et al. 2010, a minimum sample size for this study is 250 . Because of the low response rate faced by the previous study in the Malaysian public sector, this study decided to implement oversampling which doubles up the number. Therefore, in total, five hundred (500) organizations identified as a respondent for this study and questionnaires were distributed. After 2 months of the data collection period, only 226 questionnaires were collected. After the data preparation process and examined for missing data and suspicious response patterns, only 169 data were analysed for further data analysis.

From 169 valid responses, $36.1 \%$ were from the Federal agencies, State Statutory agencies by $17.8 \%$, Federal Statutory agencies by $16.6 \%$, Local Authority by $16 \%$ and followed with State agencies by $13.6 \%$. Majority of the respondents were located in the Klang Valley area consist of Wilayah Persekutuan Putrajaya by $39 \%$, Wilayah Persekutuan Kuala Lumpur by $17.2 \%$ and Selangor by $10.1 \%$. These can be explained that the majority of the government agencies especially Federal agency are centrally located at Wilayah Persekutuan Putrajaya and scatted around Wilayah Persekutuan Kuala Lumpur and Selangor. 
Next, all item measurements are derived from previous studies that have been proven its validity and reliability. All items have been adapted and adjusted to coincide with the context of this research TOE and IS Success Model construct. Five-point Likert scales ranging from " $1=$ strongly disagree" to " 5 = strongly agree" were used.

\section{DATA ANALYSIS AND RESULTS}

The methodology for measuring the research model of this study was structural equation modelling (SEM) based partial least squares (PLS), SmartPLS M3 2.0 software. This approach has multiple advantages over other methods such as multiple regressions. SEM-PLS are a popular structural equation modelling technique to conduct data analysis.

Confirmatory factor analysis was performed to measure the reliability and uniqueness (dimensionality) of the items. As suggested, we used factor loading, composite reliability (CR) and average variance extracted (AVE) to assess convergent validity. The loadings of all items have exceeded the recommended value of 0.5 , except for one (1) item in the measures of organizational readiness, perceived risk and top management support that below the recommended value, which are dropped out for future analysis.

Based on Table 1, the CR value, which shows how constructive indicators indicate the latent construct, exceeds the recommended 0.7 , ranging from 0.763 to 0.965 . The AVE, which reflects the overall amount of variance in the indicators accounted for by the latent construct, were in the range of 0.523 and 0.837 which exceeded the recommended value of 0.5 . This suggested that there was adequate convergent validity in all measures.

Table 1: Measures Validity and Reliability

\begin{tabular}{|c|c|c|c|c|}
\hline Variables & Factor Loading & AVE & CR & "Cronbach's Alpha \\
\hline \multirow[t]{3}{*}{ Relative Advantage } & 0.862 & 0.776 & 0.965 & 0.959 \\
\hline & 0.887 & & & \\
\hline & 0.885 & & & \\
\hline \multirow[t]{4}{*}{ Compatibility } & 0.849 & 0.737 & 0.918 & 0.881 \\
\hline & 0.874 & & & \\
\hline & 0.894 & & & \\
\hline & 0.814 & & & \\
\hline \multirow[t]{3}{*}{ Perceived Risks } & 0.929 & 0.837 & 0.911 & 0.853 \\
\hline & 0.812 & & & \\
\hline & NA* & & & \\
\hline Top Management & $\mathrm{NA}^{*}$ & 0.523 & 0.763 & 0.643 \\
\hline \multirow[t]{3}{*}{ Support } & 0.616 & & & \\
\hline & 0.724 & & & \\
\hline & 0.802 & & & \\
\hline \multirow[t]{3}{*}{ Organizational Readiness } & NA* & 0.555 & 0.861 & 0.799 \\
\hline & 0.799 & & & \\
\hline & 0.722 & & & \\
\hline
\end{tabular}




\begin{tabular}{lcccc}
\hline \hline Variables & Factor Loading & AVE & CR & Cronbach's Alpha \\
\hline & 0.724 & & & \\
& 0.680 & & & \\
& 0.792 & & & \\
\hline Government Regulatory & 0.637 & 0.603 & 0.883 & \\
& 0.704 & & & \\
& 0.832 & & & \\
& 0.796 & & & \\
& 0.726 & 0.551 & 0.859 & \\
\hline External IS Support & 0.738 & & & \\
& 0.714 & & & \\
& 0.834 & & & \\
& 0.864 & 0.796 & 0.921 & \\
\hline Operational Effectiveness & 0.791 & & & \\
& 0.960 & & & \\
\hline \hline
\end{tabular}

Notes: NA* items were deleted due to low loading

Discriminant validity is supported when the square root of the average variant extracted for each latent construct is highest in its assigned construct. The evidence for the discriminant validity between dimensions is given by comparing the correlation between the square roots of the AVE among constructs. The results in Table 2 shows that the correlation of each construct is smaller than the value of the square root of the AVE extracted by the index measuring the construct, thus indicating sufficient validity of discrimination. Overall, the measurement model confirmed adequate convergent validity and discriminant validity.

Table 2: Discriminant Validity of Latent Variables

\begin{tabular}{r|ccccccccc}
\hline \hline & RA & COMP & RISKS & TMS & ORS & GOVT & EXT & IMPL & OPEF \\
\cline { 2 - 9 } RA & $\mathbf{0 . 8 8 1}$ & & & & & & & & \\
COMP & 0.646 & $\mathbf{0 . 8 5 8}$ & & & & & & & \\
RISKS & 0.110 & 0.144 & $\mathbf{0 . 9 1 5}$ & & & & & & \\
TMS & 0.272 & 0.369 & -0.094 & $\mathbf{0 . 7 2 3}$ & & & & & \\
ORS & 0.204 & 0.312 & 0.054 & 0.314 & $\mathbf{0 . 7 4 5}$ & & & \\
GOVT & 0.270 & 0.316 & 0.122 & 0.272 & 0.469 & $\mathbf{0 . 7 4 2}$ & & \\
EXT & 0.213 & 0.220 & 0.129 & 0.270 & 0.549 & 0.537 & $\mathbf{0 . 7 7 6}$ & & \\
IMPL & 0.348 & 0.270 & 0.021 & 0.049 & 0.263 & 0.353 & 0.306 & $\mathbf{1 . 0 0}$ & \\
OPEF & 0.450 & 0.491 & 0.125 & 0.303 & 0.395 & 0.431 & 0.380 & 0.184 & $\mathbf{0 . 8 9 2}$ \\
\hline \hline
\end{tabular}

Notes: Items on the diagonal are square roots of $A V E$ scores.

Lastly, the causal relationship between variables is examined through a structural model analysis. The path coefficient and t-value analysis can approve data to support hypothesis models. To run this analysis, statistical significance was assessed by t-tests based on a bootstrap procedure with 5,000 bootstrapping. This study begins our interpretation with the hypothesized factors. Table 3 shows a summary of the structural model in this study. 
Table 3: Results of Hypothesis Testing

\begin{tabular}{|c|c|c|c|c|c|}
\hline Hypothesis & $\begin{array}{c}\text { Path Relationship Between } \\
\text { Variables }\end{array}$ & $\begin{array}{c}\text { Path } \\
\text { Estimatio } \\
\text { n }(\beta)\end{array}$ & $\begin{array}{c}t \\
\text { Valu } \\
\mathrm{e}\end{array}$ & $\begin{array}{c}p- \\
\text { Value }\end{array}$ & Results \\
\hline H1 & RA -> IMPLEMENTATION & $0.194^{* * *}$ & 3.585 & 0.000 & Supported \\
\hline $\mathrm{H} 2$ & COMP -> IMPLEMENTATION & $0.086^{* * *}$ & 3.719 & 0.000 & Supported \\
\hline $\mathrm{H} 3$ & RISKS -> IMPLEMENTATION & $-0.017^{*}$ & 1.665 & 0.098 & Supported \\
\hline $\mathrm{H} 4$ & TMS -> IMPLEMENTATION & $0.160^{* * *}$ & 2.731 & 0.007 & Supported \\
\hline H5 & ORS -> IMPLEMENTATION & $0.145^{* * *}$ & 2.798 & 0.006 & Supported \\
\hline H6 & EXT -> IMPLEMENTATION & $-0.037^{\mathrm{ns}}$ & 1.072 & 0.285 & Not Supported \\
\hline $\mathrm{H} 7$ & GOVT -> IMPLEMENTATION & $-0.070^{\mathrm{ns}}$ & 1.161 & 0.247 & Not Supported \\
\hline H8 & $\begin{array}{l}\text { IMPLEMENTATION -> } \\
\text { OPERATIONAL } \\
\text { EFFECTIVENESS }\end{array}$ & $0.267^{* * *}$ & 3.977 & 0.000 & Supported \\
\hline
\end{tabular}

Note: Significant level $=* * * \mathrm{p}<0.01 ; * * \mathrm{p}<0.05 ; * \mathrm{p}<0.10$; ns not significant for one-tailed t-test

RA=Relative Advantage; COMP=Compatibility; RISK=Perceived Risks; ORS=Organizational Readiness; TMS=Top management support; EXT=External Vendor Support; GOVT=Government Regulatory

The next step of structural model evaluation criteria analysis is the determination of $\mathrm{R}^{2}$. The $\mathrm{R}^{2}$ provides the percentage of variation in dependent variable(s) explained by the independent variable(s) (Keil et al., 2000). The $\mathrm{R}^{2}$ value is one of the methods that can be used to predict model accuracy in which a higher value of $\mathrm{R}^{2}$ means a higher level of predictive accuracy. The value of $\mathrm{R}^{2}$ varies according to the number of measuring an independent variable(s) i.e. a higher number of independent variable needs to produce a higher value of $\mathrm{R}^{2}$ and vice-versa (Chin, 1998). Furthermore, the rule of thumb for acceptable $\mathrm{R}^{2}$ according to Chin (1998) that model having R2 as $0.67,0.33$, and 0.19 are considered as substantial, moderate, and weak respectively.

The result shown in Table 4 revealed that the $\mathrm{R}^{2}$, both initiation and implementation of cloud-based services and resources by the Malaysian public sector falls under the moderate level that explained by Technology, Organization and Environment factors, $41 \%$ for Initiation and together explained $50.2 \%$ or half of the variance for implementation. However, only $16.9 \%$ of the variance for consequences by the cloud computing assimilation in the Malaysian public sector has been verified in this study.

Table 4: Result of $\mathrm{R}^{2}$

\begin{tabular}{lc}
\hline \hline Latent Variable & $\mathbf{R}^{\mathbf{2}}$ Value \\
\hline Implementation & 0.502 \\
Operational Effectiveness & 0.169 \\
\hline \hline
\end{tabular}

\section{DISCUSSION}

The relative advantage was found to be the strongest total effect of the relationship between technological factors and initiation as well as implementation. The relative advantage was found to be a significant determinant of technology adoption in previous studies among organizations, 
firms and industries, including those related to e-commerce applications, Internet and e-business technologies, Internet-based ICT, e-commerce, and RFID adoption as well as cloud computing (Sallehudin et al., 2019). With regard to the relative advantage in this study, it can be argued that the organization's initiation and actual implementation of cloud computing can be adequately predicted based on the relative advantage factors. One possible explanation for the relative advantage being significant in this study is the diverse types of cloud computing being adopted, with the belief that it provided a relatively greater improvement over their previous IT infrastructure.

Compatibility was also found to be the strongest total effect of the relationship between technological factors and the implementation of cloud computing by the Malaysian public sector. This finding is consistent with earlier findings in other previous IT adoption studies among organizations, firms and industries, including those related to e-commerce applications, enterprise application and e-business technologies by (Alam et al., 2011) that found compatibilities are significant to IT implementation. It can be argued that agencies perceived cloud computing as being compatible and consistent with their potential needs, and prior experience with the existing agency's policies, practices, and IT infrastructure. The cloud computing features that are compatible with all aspects of IT services in the Malaysian public sector lead to a higher level of implementation among the agencies. Most agencies in the Malaysian public sector also found that cloud computing services are completely compatible with the current IT system in their department, thus influencing cloud computing implementation.

Perceived risks were hypothesized to have a negative influence or barrier factors on the implementation of cloud-based services in the Malaysian public sector. This study found significant support for the relationship between perceived risks as a barrier factor on the implementation of cloud computing services and resources by the Malaysian public sector. This finding is consistent with findings in the other previous IT adoption studies by Akturan and Tezcan (2012). This finding is also consistent with the perception by Armbrust et al. (2010), Buyya et al. (2011) and Wyld (2010), which stated that security plays the main dominant factors of a barrier to cloud computing implementation. It can be argued that agencies believe that the risks of cloud computing may affect their implementation of the cloud environment, especially the public cloud. This is particularly true in the Malaysian public sector because the agency's data requires a more secure environment for storage and retrieval. Privacy issues are also a critical concern in the public sector industry (Wyld, 2009). In addition, information and data confidentiality and privacy issues in a cloud computing environment also turn to be significant to the Malaysian public sector to implement this IT innovation.

Top management's support and organizational readiness were found to be a significant organizational factor in determining the implementation of cloud computing by the Malaysian public sector. Top management's support in an organization is important to enhance the diversity of cloud computing. Moreover, intensive cloud computing services and resources require top managers to continuously provide commitments and support to facilitate cloud computing projects (Wyld, 2010). This finding is consistent with findings mentioned in the other previous IT adoption studies such as enterprise resource planning application, e-commerce, Web 2.0, electronic supply chain and business intelligence applications by Akca and Ozer (2014) and Xin et al., (2014) that stated the top management plays a significant role in enhancing IT innovation implementation in an organization. The positive effect of top management support may be even more significant in 
the cloud computing service and resource context. It can be argued that cloud computing is a complex organizational IT innovation involving a transformation in business processes and strategies. Unlike e-business, ERP, e-commerce or other IT innovations, cloud computing services and resources assimilation involves more complex organizational restructuring and transformation. Therefore, continuous and practical supports from top managers may be more critical for cloud computing services and resources engagement than other IT engagements. It can be argued that the significant findings of top management support in cloud computing implementation extend the cumulative knowledge of top managers' role in innovation implementation of cloud computing. That is, in the context of complex innovation, such as cloud computing, the power and influence of top managers remain substantial and necessary for diffusing and routinizing innovation within the Malaysian public sector.

Organizational readiness was found to have a significant effect on the implementation of cloud computing assimilation by the Malaysian public sector. This is consistent with the findings in other previous IT adoption studies such as green IT, RFID technology, enterprise systems and internet and web technology which found that organizations with more IT resources have more abilities to implement IT innovation. In studies specific to cloud computing adoption, organizational readiness was a positive significant factor in the study (Hassan et al., 2017).

External IS support and government regulatory factors were found to have no significant to the implementation of cloud computing in the Malaysian public sector. The result of this study is consistent with the findings in Alkhater et al., (2014) and Dahiru et al., (2014) that found external IS support was insignificant to cloud computing adoption. In addition, the result of this study also supports the results of the study by Lin (2013), and Ramdani et al. (2009) that found external IS support was insignificant to the IT adoption. Thus, it can be argued that the effect of external IS support on initiation and implementation of cloud computing, especially from vendors, may be different for each organization. Not all organizations received support from the same vendors for the same solutions provided. However, the involvement of vendors to introduce cloud computing solutions to organizations may provide the foundational motivation to the organization to evaluate the potential benefits of cloud computing services and resources. These arguments are supported by the significant relationship between external IS support and cloud computing initiation. Government regulatory support in this study is viewed as the promotion, direction and support from MAMPU as the main agency for IT administration and policy makers in the Malaysian public sector. The study found that all the promotion, direction and support from MAMPU only influence other agencies in the Malaysian public sector to initiate the potential benefits of cloud computing services and resources but not enough to influence some of the agencies to actually implement it. The policy, directive and promotion from MAMPU seem to be only taken as guidelines and the advice is not mandatory for cloud computing assimilation. Thus, it only provides the foundational intention for the organization to evaluate the potential benefits of cloud computing services and resources but not the direction for their actual implementation.

As expected, the implementation of cloud computing significantly affects the organization's operational effectiveness thus, providing evidence to support the hypothesis $\mathrm{H} 8$ of this study. The result of this study is consistent with the finding by Ainin et al., (2015) and Tseng and Liao (2015) that emphasized IT innovation implementation and use have a positive impact on several dimensions of organizational performance. In this regard, the consequence of organizational performance measured in this study is operational effectiveness. According to Kundra (2011) and 
Wyld (2010), the public sector will gain an advantage to their IT operation and services by implementing cloud computing. Therefore, the results confirm that the extent of cloud computing implementation by the Malaysian public sector influences and is able to reduce IT operational cost, improve productivity and enhance service delivery systems. Although the study found a significant relationship between assimilation and impact, the variance effect of operational effectiveness and actual implementation is only 0.169 or $16.9 \%$. According to Gangwar et al., (2015), to gain value and take full advantage of IT innovation implementation, organizations should make efforts to fully routinize, and make full use of the cloud computing. In addition, another consideration to improve the value of operational effectiveness is a complete integration of IT systems into cloud computing of the Malaysian public sector.

\section{CONCLUSIONS, LIMITATIONS AND FUTURE RESEARCH}

This study was motivated to explore the relationship of the TOE framework toward the implementation of cloud computing in the Malaysian public sector as well as the operational effectiveness for its implementation. The study found that all technological and organizational factors are influencing the implementation of cloud computing. However, environmental factors found to not significant. By understanding the factors enhancing the implementation of a cloud computing, the IT Manager or Decision Makers can consider these factors during the ICT Strategic Planning blueprint development as part of the agency's objective, action and KPI to implement cloud computing. Further, the IT manager needs to engage decision maker in the development and implementation phases to enhance cloud computing. These practices will help to maintain effective communications between the top management, IT division and cloud provider and ensure the continuity of cloud usage and utilization in agencies.

Although this study has produced interesting findings in term of presenting an extended model of an organization's assimilation process, these findings carry important limitation which is relevant for future research. This study limitation is the subjectivity of classifying cloud computing deployment strategies (public, private, and hybrid) and delivery strategies (IaaS, PaaS, and SaaS). In this study, the approached agencies initially were only asked whether they implement any of the thirteen-cloud computing in their agencies. Therefore, this study is unable to classify delivery and deployment strategies of cloud computing implementation by the Malaysian public sector. Another important factor for cloud computing, such as cost factors, is missing in this study. The cost of adopting an innovation includes initial setup cost, fixed as well as variable operational cost.

The study has achieved its research objectives to construct the implementation framework of the cloud computing services and resources in the Malaysian public sector based on the TOE and IS success model. It has been developed and validated by robust statistical analyses. The results generated based on the proposed assimilation framework of cloud computing in the Malaysian public sector. It also can be used as empirical evidence for the decision makers in the public sector to provide a plan for the successful adoption and implementation of cloud computing in the Malaysian public sector. The results also can help the vendors and developers of cloud computing to enhance the existing cloud computing support in order to meet the requirements and needs of the public sector agencies. 


\section{ACKNOWLEDGEMENTS}

This research was co-sponsored by the Centre for Software Technology and Management (SOFTAM) of Faculty of Information Science and Technology, National University of Malaysia (UKM), Malaysian Administrative Modernisation and Management Planning Unit (MAMPU) and Public Service Department (PSD) of Prime Minister's Department.

\section{REFERENCES}

Ainin, S., Parveen, F., Moghavvemi, S., Jaafor, N. I., \& Shuib, N. L. M. (2015). Factors influencing the use of social media by SMEs and its performance outcomes. Industrial Management \& Data Systems, 115(3), 570-588.

Akca, Y., \& Ozer, G. (2014). Diffusion of innovation theory and an implementation on enterprise resource planning systems. International Journal of Business and Management, 9(4), 92114.

Akturan, U., \& Tezcan, N. (2012). Mobile banking adoption of the youth market: Perceptions and intentions. Marketing Intelligence \& Planning, 30(4), 444-459.

Alam, S. S., Ali, M. Y., \& Mohd. Jani, M. F. (2011). An emperical study of factors affecting electronic commerce adoption among SMEs in Malaysia. Journal of Business Economics and Management, 12(2), 375-399.

Alkhater, N., Wills, G., \& Walters, R. (2014). Factors influencing an organisation's intention to adopt cloud computing in Saudi Arabia. International Conference on Cloud Computing Technology and Science, , (pp. 1040-1044). Nanyang Avenue, Singapore.

Alshamaila, Y., \& Papagiannidis, S. (2013). Cloud computing adoption by SMEs in the north east of England: A multi-perspective framework. Journal of Enterprise Information Management, 26(3), 250-275.

Amron, M. T., Ibrahim, R., Chuprat, S., \& Abu Bakar, N. A. (2018). Preliminary study on the implementation of 1govcloud among public agencies in Malaysia. Open International Journal of Informatics (OIJI), 6(4), 92-103.

Armbrust, M., Stoica, I., Zaharia, M., Fox, A., Griffith, R., Joseph, A. D., Katz, R., Konwinski, A., Lee, G., Patterson, D., \& Rabkin, A. (2010). A view of cloud computing. Communications of the ACM, 53(4), 50-58.

Ayyash, M. M., Ahmad, K., \& Singh, D. (2012). A hybrid information system model for trust in e-government initiative adoption in public sector organisation. International Journal of Business Information Systems, 11(2), 162.

Borgman, H. P., Bahli, B., Heier, H., \& Schewski, F. (2013). Cloudrise: Exploring cloud computing adoption and governance with the TOE framework. 46th Hawaii International Conference on System Sciences, 4425-4435. Hawaii, US.

Buyya, R., Broberg, J., \& Goscinski, A. (2011). Cloud Computing Principles and Paradigms. John Wiley \& Sons, Inc., Hoboken, New Jersey.

Buyya, R., Yeo, C. S., Venugopal, S., Broberg, J., \& Brandic, I. (2009). Cloud computing and emerging IT platforms: Vision, hype, and reality for delivering computing as the 5th utility. Future Generation Computer Systems, 25(6), 599-616.

Chen, C. (2013). Perceived risk, usage frequency of mobile banking services. Managing Service Quality, 23(5), 410-436. 
Chin, W. W. (1998). Issues and opinion on structural equation modeling. MIS Quarterly, 22(1), vii-Xvi.

Craig, R., Frazier, J., Jacknis, N., Murphy, S., Purcell, C., Spencer, P., \& Stanley, J. (2009). Cloud Computing in the Public Sector: Public Manager's Guide to Evaluating and Adopting Cloud Computing. In White Paper. Cisco Internet Business Solutions Group.

Dahiru, A. A., Bass, J. M., \& Allison, I. K. (2014). Cloud Computing: a Comparison of Adoption Issues Between UK and Sub-Saharan Africa SMEs. European, Mediterranean \& Middle Eastern Conference on Information Systems. Doha, Qatar.

Davis, F. D. (1989). Perceived Usefulness, Perceived Ease of Use, and User Acceptance of Information Technology. MIS Quarterly, September.

DeLone, W. H., \& McLean, E. R. (1992). Information systems success: The quest for the dependent. Information Systems Research, 3(1), 60-95.

DeLone, W. H., \& McLean, E. R. (2003). The DeLone and McLean model of information systems success: a ten-year update. Journal of Management Information Systems, 19(4), 9-30.

Gangwar, H., Date, H., \& Ramaswamy, R. (2015). Understanding determinants of cloud computing adoption using an integrated TAM-TOE model. Journal of Enterprise Information Management, 28(1), 107-130.

Gewald, H., \& Dibbern, J. (2009). Risks and benefits of business process outsourcing: A study of transaction services in the German banking industry. Information \& Management, 46(4), $249-257$.

Ghobakhloo, M., \& Tang, S. H. (2015). Information system success among manufacturing SMEs: case of developing countries. Information Technology for Development, 1102(January), $1-28$.

Hassan, H., Mohd Nasir, M. H., Norhaiza, K., \& Adon, I. (2017). Factors influencing cloud computing adoption in small and medium enterprises. Journal of ICT, 16(1), 21-41.

Hong, W., \& Zhu, K. (2006). Migrating to internet-based e-commerce: Factors affecting ecommerce adoption and migration at the firm level. Information \& Management, 43(2), 204-221.

Horst, M., Kuttschreuter, M., \& Gutteling, J. M. (2007). Perceived usefulness, personal experiences, risk perception and trust as determinants of adoption of e-government services in The Netherlands. Computers in Human Behavior, 23(4), 1838-1852.

Jaatun, M., Lambrinoudakis, C., \& Rong, C. (2012). Special issue on security in cloud computing. Journal of Cloud Computing: Advances, Systems and Applications, 1(17).

Kaliannan, M., Raman, M., \& Dorasamy, M. (2009). ICT in the context of public sector service delivery : A Malaysian perpective. WSEAS Transactions on Systems, 8(4), 543-556.

Keil, M., Tan, B. C. Y., Wei, K.K., Saarinen, T., Tuunainen, V., \& Wassenaar, A. (2000). A crosscultural study on escalation of commitment behavior in software projects. MIS Quarterly, 24(2), 299-325.

Laudon, K. C., \& Laudon, J. P. (2010). Management Information Systems: Managing the Digital Firm. Upper Saddle River, Pearson.

Li, M., Zhao, D., \& Yu, Y. (2015). TOE drivers for cloud transformation: direct or trust-mediated? Asia Pacific Journal of Marketing and Logistics, 27(2), 226-248.

Lin, H. F. (2012). Examining the factors influencing knowledge management system adoption and continuance intention. Knowledge Management Research \& Practice, 11(4), 389-404.

Lin, H. F. (2013). Understanding the determinants of electronic supply chain management system adoption: Using the technology-organization-environment framework. Technological Forecasting and Social Change, 86, 80-92. 
Low, C., Chen, Y., \& Wu, M. (2011). Understanding the determinants of cloud computing adoption. Industrial Management \& Data Systems, 111(7), 1006-1023.

Maclennan, E., \& Belle, J. Van. (2014). Factors affecting the organizational adoption. Information Systems and E-Business Management, 12(1), 71-100.

MAMPU. (2000). Rangka Dasar Keselamatan Teknologi Maklumat dan Komunikasi Kerajaan. Pekeliling Am Bilangan 3 Tahun 2000, 5261(2). Retrieve from https://www.mampu.gov.my/images/agensikerajaan/perkhidmatan/pa032000.pdf.

MAMPU (2011). Garis Panduan Pengurusan Pusat Data, The Malaysian Public Sector Consolidated Data Centre and DRC Initiative. Retrieve from https://www.mampu.gov.my/ms/penerbitan-mampu/send/121-seminar-personel-ictsektor-awam-2011/358-4-pn-salmah-garispanduan-pengurusan-pusat-data

MAMPU. (2015). Garis Panduan Permohonan Kelulusan Teknikal dan Pemantauan Projek Teknologi Maklumat dan komunikasi (ICT) Agensi Sektor Awam. Surat Pekeliling Am Bilangan 3 Tahun 2015, 1, 1-5.

Meri, A., Hasan, M. K., Danaee, M., Jaber, M., Jarrar, M., Safei, N., Dauwed, M., Abd, S. K., \& Al-bsheish, M. (2019). Modelling the utilization of cloud health information systems in the Iraqi public healthcare sector. Telematics and Informatics, 36(April 2018), 132-146.

Mohammed, F., \& Ibrahim, O. (2015). Models of adopting cloud computing in the e-government context. Jurnal Teknologi, 73(2), 51-59.

Moore, G. C., \& Benbasat, I. (1991). Development of an instrument to measure the perceptions of adopting an information technology innovation. Information Systems Research, 2(3), 192-222.

Mukred, A., Singh, D., \& Safie, N. (2017). Investigating the impact of information culture on the adoption of information system in public health sector of developing countries. International Journal of Business Information Systems, 24(3), 261.

Oh, K., Anderson, A. R., \& Cruickshank, D. (2012). Perceived barriers towards the use of e-trade processes by Korean SMEs. Business Process Management Journal, 18(1), 43-57.

Premkumar, G. (2003). A meta-analysis of research on information technology implementation in small business a meta-analysis of research on information technology implementation in small business. Journal of Organizational Computing and Electronic Commerce, 13(2), 91-121.

Ramamurty, K. (1990). Role of environmental, organisational, and technological factors in information technology implementation in advance manufacturing: an innovation adoption-diffusion perspective (Doctoral dissertation, The University of Pittsburgh, USA).

Ramdani, B., Chevers, D., \& Williams, D. A. (2013). SMEs' adoption of enterprise applications: A technology-organisation-environment model. Journal of Small Business and Enterprise Development, 20(4), 735-753.

Ramdani, B., Kawalek, P., \& Lorenzo, O. (2009). Predicting SMEs' adoption of enterprise systems. Journal of Enterprise Information Management, 22(1/2), 10-24.

Rogers, E. M. (2003). Diffusion of innovations. 5th edition, New York: Free Press.

Sallehudin, H., Razak, R. C., \& Ismail, M. (2016). Determinants and impact of cloud computing implementation in the public sector. Journal of Advances in Information Technology, 7(May), 245-251.

Sallehudin, H., Razak, R. C., Ismail, M., Fadzil, A. F. M., \& Baker, R. (2019). Cloud computing implementation in the public sector: Factors and impact. Asia-Pacific Journal of Information Technology and Multimedia, 7(2-2), 27-42. 
Syed, R., Bandara, W., French, E., \& Stewart, G. (2018). Getting it right! Critical success factors of BPM in the public sector: A Systematic Literature Review. Australasian Journal of Information Systems, 22(0).

Tarute, A., \& Gatautis, R. (2014). ICT impact on SMEs performance. Procedia - Social and Behavioral Sciences, 110, 1218-1225.

Tornatzky, L. G., \& Fleischer, M. (1990). The processes of technological innovation. Lexington, MA: Lexington Books.

Tseng, P. H., \& Liao, C. H. (2015). Supply chain integration, information technology, market orientation and firm performance in container shipping firms. The International Journal of Logistics Management, 26(1), 82-106.

Williams, B. (2012). The Economics of Cloud Computing: An Overview for Decision Maker. Cisco Press.

Wyld, D. C. (2009). Moving to the Cloud: An Introduction to Cloud Computing in Government E-Government Series. IBM Center for the Business of Government.

Wyld, D. C. (2010). The cloudy future of government IT: Cloud computing and the public sector around the world. International Journal of Web \& Semantic Technology (IJWesT), 1(1), $1-20$.

Xin, J. Y., Ramayah, T., Soto-Acosta, P., Popa, S., \& Ai Ping, T. (2014). Analyzing the use of web 2.0 for brand awareness and competitive advantage: An empirical study in the malaysian hospitability industry. Information Systems Management, 31(2), 96-103.

Yusof, M. M., \& Arifin, A. (2016). Towards an evaluation framework for Laboratory Information Systems. Journal of Infection and Public Health, 9(6), 766-773. 